\title{
Transport of six tyrosine kinase inhibitors: active or passive?
}

\author{
Richard J. Honeywell, Sarina Hitzerd, letje Kathmann, Godefridus J. Peters* \\ Department of Medical oncology, VU university medical center, Amsterdam, The Netherlands
}

*Corresponding Author: E-mail: gj.peters@vumc.nl; Tel.: +31 (20) 4442633

Received: February 22, 2016; Published: March 31, 2016

\begin{abstract}
Transport of erlotinib, gefitinib, sorafenib, sunitinib, dasatinib and crizotinib can be active or passive, which was studied by measuring uptake at low $\left(4^{\circ} \mathrm{C}\right.$; passive) and normal temperature $\left(37^{\circ} \mathrm{C}\right.$; active and passive) and by the use of specific organic cation transporter (OCT) inhibitors. Intracellular accumulation was determined using Caco-2 as monolayers, while for gut permeation we used differentiated Caco-2 as model for intestinal epithelium in the Transwell system. Sorafenib and crizotinib uptake are likely to be dependent on passive transport. Gefitinib, dasatinib and sunitinib uptake seem to be active. Erlotinib's transport also seems to be active. This study suggests that hOCTs might be involved in the apical to basolateral transport of gefitinib and crizotinib. Overall it can be concluded that the accumulation and transport of these six TKIs are very different, despite the fact that they are all tyrosine kinase inhibitors.
\end{abstract}

\section{Keywords}

Tyrosine kinase; drug transport; erlorinib; gefitinib; sorafenib; sunitinib; dasatinib; crizotinib

\section{Introduction}

Protein kinases are key regulator enzymes of cell function via the transfer of a phosphate group from ATP to a protein in a cell [1]. One of the subgroups is the tyrosine kinases (TK) family. These kinases attach phosphate groups to the amino acid tyrosine of a protein, controlling a wide range of properties in proteins such as, but not limited to, differentiation, apoptosis, enzyme activity, subcellular localization and interaction between molecules [2]. Subsequently, TKs function in many signaling transduction cascades, controlling fundamental cellular processes including cell cycle, migration, survival, proliferation and metabolism [3]. Receptor TKs consist of an extracellular ligand binding domain which is connected to the cytoplasmic domain by a single trans-membrane helix. The binding of a ligand to the receptor induces dimerization resulting in internal activation of the RTK [4,5]. Mutations in the ATP-binding site can cause some TKs to become constitutively active which results in a non-stop functional state that may contribute to initiation or progression of cancer [6]. Small molecule tyrosine kinase inhibitors (TKIs) were developed to inhibit TK function. In this study, six different TKIs were investigated. Erlotinib and gefitinib are reversible inhibitors of the epidermal growth factor receptor tyrosine kinase (EGFR) [7] and are approved for treatment of non-small-cell lung cancer (NSCLC) [8-10]. Sorafenib is a multiple kinase inhibitor which inhibits multiple intracellular (CRAF, (mutant) BRAF) and receptor cell surface kinases (KIT, FLT-3, RET, VEGFR-1/2/3, and PDGFR- $\beta$ ) [11]. Sorafenib is approved for liver (hepatocellular carcinoma (HCC)) and kidney (renal cell carcinoma $(\mathrm{RCC})$ ) cancer $[12,13]$. Sunitinib is also a multi-targeted receptor TKI which is 
known to inhibit VEGFR, PDGFR, KIT, RET, CSF-1 and Flt3 [14]. Sunitinib is FDA approved for multiple cancer types, namely gastrointestinal stromal tumor (GIST), kidney cancer (RCC) and pancreatic neuroendocrine tumors (pNET) [15-17]. Dasatinib is a BCR-ABL inhibitor, but can also inhibit PDGFR, c-KIT, Src and the ephrin A receptor [18]. Dasatinib was FDA approved for the treatment of chronic myeloid leukemia (CML) [19]. Crizotinib is a MET/ALK multi-targeted (ALK, ROS1, CMET) receptor TKI approved for NSCLC [20,21].

Generally, TKIs are poorly soluble in aqueous solutions, leading to poor bioavailability $[22,23]$. This may also affect uptake and efflux of these compounds. Efflux is mediated by ATP-dependent efflux pumps of the ATP-binding cassette (ABC) family, such as BCRP (ABCG2), P-gp (ABCB1) and multidrug resistance protein 1 (MRP1) [24-26]. Influx pumps include the organic cation transporters (OCTs). Since several TKIs have a cationic charge and high lipophilicity, they are substrates for OCTs $[22,27,28]$.

TKIs are oral drugs that have to pass the intestine barrier to enter the systemic circulation. Therefore, transport proteins on the intestinal epithelia are very important in the drug bioavailability and resistance mechanisms [22,29]. The human colon carcinoma cell line Caco-2 mimics the epithelial monolayer, which covers the inner intestinal wall and has been used as a model system for drug investigation [30] (Figure 1). The hOCT1 (basolateral) and hOCT3 (apical) are known to be functional present at the intestinal level (Caco2 cells) [31,32]. We recently validated the Caco-2 permeable cell culture system for permeation of several TKIs [33] and applied it to determine the role of various drug transporters in permeability and absorption of erlotinib, gefitinib, sorafenib, sunitinib, dasatinib and crizotinib, by using several specific inhibitors of these pumps.

\section{Materials and Methods}

\section{Materials}

Erlotinib, gefitinib, sorafenib, sunitinib, dasatinib, crizotinib were from LC Laboratories (Woburn, USA). Amantadine, $\beta$-estradiol, cimetidine and verapamil were purchased from Sigma (St. Louis, MO, USA). Desipramine was from ICN Biochemicals (Aurora, $\mathrm{OH}$, USA). All above drugs were ultimately diluted in DMSO.

Dulbecco's modified eagle medium (DMEM), trypsin-EDTA, penicillin/streptomycin ( $\mathrm{p} / \mathrm{s} ; 10000 \mathrm{U} / \mathrm{ml}$ ) and $1 \mathrm{M}$ HEPES buffer (in $0.85 \% \mathrm{NaCl}$ ) were purchased from Lonza Benelux BV (Breda, The Netherlands). Phosphate buffered saline (PBS) was purchased from B. Braun Medical BV (Oss, The Netherlands). Fetal bovine serum (FBS) was purchased from PAA Laboratories $\mathrm{GmbH}$ (Pasching, Austria). Bovine serum albumin fraktion V (BSA) was purchased from Roche Diagnostics $\mathrm{GmbH}$ (Mannheim, Germany). Analytical grade solvents like acetonitrile, methanol and isopropanol were purchased from Biosolve BV (Valkenswaard, The Netherlands). Bio-Rad protein assay was purchased from Bio-Rad Laboratories GmbH (München, Germany). MilliQ water was supplied via a MilliQ water purification system (Millipore, The Netherlands).

The BIOCOAT ${ }^{\oplus}$ HTS Caco-2 assay system was purchased from Becton Dickinson BV (Breda, The Netherlands). Breathe-easy microplate sealing film was purchased from Diversified Biotech BV (Ulvenhout, The Netherlands). The Trans epithelial electrical resistance (TEER) meter (Millicell ${ }^{\circledR}$ - ERS) was provided by Millipore (Amsterdam, The Netherlands). LC-MS/MS analyses were performed using a Dionex Ultimate 3000 system coupled with an API 3000 mass spectrometer (Applied Biosciences SCIEX). For this system the following software was used: Analyst version 1.5.2 from Applied Biosciences in combination with Dionex, Chromeleon LC modules version 6.8, controlled by Dionex mass link (DMS) version 2.10. 


\section{Cell culture}

The Caco-2 cell line, originating from a colorectal adenocarcinoma, was cultured in DMEM supplemented with $10 \% \mathrm{FBS}$ and $20 \mathrm{mM}$ HEPES at $37{ }^{\circ} \mathrm{C}, 5 \% \mathrm{CO}_{2}$ and $100 \%$ humidity [31,33]. Under normal culture conditions Caco-2 cells behave like a colon cancer cell in which no polarization at apical or basolateral side is found. Using a special coating in a transwell, the cell line differentiates and when confluent, forms a cellular layer with specific transporter expression at each side (Figure 1).

\section{Characterization of passive and active transport}

Active and passive transport were characterized by culturing the cells at a low temperature $\left(4{ }^{\circ} \mathrm{C}\right.$; passive transport) or a physiological temperature $\left(37^{\circ} \mathrm{C}\right.$; active and passive transport). Caco-2 cells were seeded in $2 \mathrm{ml}$ DMEM culture medium with $1 \%$ penicillin/streptomycin $(\mathrm{p} / \mathrm{s})$ in 6 -well plates at a density of $0.2 \times 10^{5}$ cells $/ \mathrm{cm}^{2}$. Cells were allowed to attach for 36 hours at $37{ }^{\circ} \mathrm{C}, 5 \% \mathrm{CO}_{2}$ and $100 \%$ humidity. Subsequently, cells were incubated at $4{ }^{\circ} \mathrm{C}$ or at $37^{\circ} \mathrm{C}$ for two hours prior to the experiment. Attached cells were than exposed to $10 \mu \mathrm{M}$ erlotinib, gefitinib, sorafenib, sunitinib, crizotinib and $1 \mu \mathrm{M}$ dasatinib for 2,4 and 6 hours at both $4{ }^{\circ} \mathrm{C}$ and $37^{\circ} \mathrm{C}$. After drug exposure medium was aspirated and cells were washed three times with $5 \mathrm{ml}$ ice cold PBS. Trypsin/EDTA $(200 \mu \mathrm{L})$ was added to each well and incubated for about 5-10 minutes at $37{ }^{\circ} \mathrm{C}, 5 \% \mathrm{CO}_{2}$ and $100 \%$ humidity. When cells were detached, the cells were re-suspended with $1 \mathrm{ml}$ ice cold PBS and transferred into eppendorf tubes. Next, cell suspension was spun down for 5 minutes at $425 \mathrm{~g}$ at $4{ }^{\circ} \mathrm{C}$. At last the supernatant was aspirated, the pellet was snap frozen in liquid nitrogen and stored at $-80{ }^{\circ} \mathrm{C}$, until analysis by the liquid chromatography coupled to mass spectrometry (LC-MS-MS) [34]. The protein content was determined using the Bio-Rad protein assay.

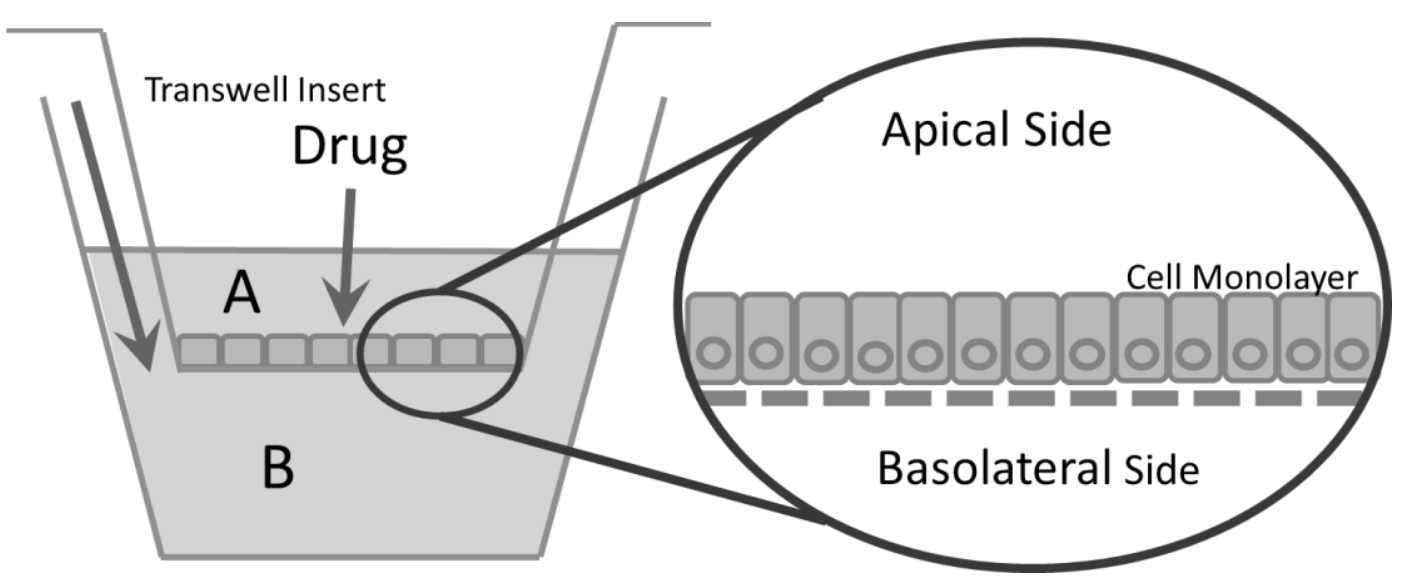

Figure 1. Caco-2 cell culture system with an apical (intestine) and basolateral (blood) side[35].

\section{Effect of specific OCT inhibitors}

Transporter inhibition studies were performed to determine whether the human organic cation transport (hOCT) family is involved in the transport and accumulation of erlotinib, gefitinib, sorafenib, sunitinib, dasatinib or crizotinib. To achieve this, Caco-2 cells were cultured as described above at $37{ }^{\circ} \mathrm{C}$. After 36 hours, to allow proper attachment, cells were exposed to either $100 \mu \mathrm{M}$ amantadine (hOCT1\&2), $100 \mu \mathrm{M}$ cimetidine (hOCT1\&2\&3) [37], $100 \mu \mathrm{M}$ desipramine (hOCT1\&2\&3), $10 \mu \mathrm{M} \beta$-estradiol (hOCT1\&3) or $10 \mu \mathrm{M}$ verapamil (hOCT1\&P-gp) [28,35,36] for $15 \mathrm{~min}$. Then attached cells were exposed to $10 \mu \mathrm{M}$ erlotinib, gefitinib, sorafenib, sunitinib, crizotinib or $1 \mu \mathrm{M}$ dasatinib for 2 hours at $37^{\circ} \mathrm{C}$. After drug exposure cells were harvested and processed as described above. 


\section{Differentiated Caco-2 cells as a model for gut epithelial transport in transwell}

Transwell studies were performed to investigate the transport of TKIs from apical (A) to basolateral (B) side through a confluent Caco-2 monolayer. The optimization and validation of this model was recently described [33]. Shortly, the Becton Dickinson Bioscience BIOCOAT ${ }^{\circ}$ HTS Caco-2 assay system was used $[37,38]$. Caco- 2 cells were plated at a density of 200,000 cells per insert $\left(6.6 \times 10^{5}\right.$ cells $\left./ \mathrm{cm}^{2}\right)$ in $500 \mu \mathrm{l}$ basal seeding medium supplemented with $0.1 \%$ lyophilized powder $\mathrm{MITO}^{+}$serum extender and $1 \% \mathrm{p} / \mathrm{s}$ (BSM supplemented). The transwell inserts were placed into a Multiwell ${ }^{\mathrm{TM}}$ Feeder Tray, covered with breatheasier cell culture foil, and incubated for $22-24 \mathrm{~h}$ at $37^{\circ} \mathrm{C}, 5 \% \mathrm{CO}_{2}$ and $100 \%$ humidity; the medium was aspirated from both apical and basolateral side and replaced with Entero-STIM ${ }^{\mathrm{TM}}$ supplemented with $0.1 \%$ lyophilized powder $\mathrm{MITO}^{+}$serum extender and $1 \% \mathrm{p} / \mathrm{s}$ (Entero-STIM ${ }^{\mathrm{TM}}$ supplemented) for 44-48 hours enabling cells to differentiate. For the permeation the Multiwe $I^{\mathrm{TM}}$ feeder tray was replaced for a FALCON ${ }^{\circ}$ 24-well plate at $37{ }^{\circ} \mathrm{C}, 5 \% \mathrm{CO}_{2}$ and $100 \%$ humidity. The medium at the apical site was replaced with $300 \mu \mathrm{l}$ Hank's buffered salt solution (HBSS), $100 \mu \mathrm{M}$ cimetidine, desipramine or $10 \mu \mathrm{M}$ verapamil (apical side) and $1 \mathrm{ml} \mathrm{HBSS}$ (basolateral side). Trans epithelial electral resistance (TEER) was measured using a Millicell-ERSvoltmeter to verify the quality of the Caco-2 cell monolayers. Monolayers with TEER values determined below $165 \Omega \mathrm{cm}^{2}$ were discarded [35]. Next, the HBSS and hOCT inhibitor solution were replaced for $300 \mu \mathrm{l}$ of $20 \mu \mathrm{M}$ erlotinib, gefitinib, sorafenib, sunitinib, dasatinib or crizotinib alone or in combination with 100 $\mu \mathrm{M}$ cimetidine, desipramine or $10 \mu \mathrm{M}$ verapamil (apical side) and $1 \mathrm{ml}$ HBSS $+5 \%$ BSA (basolateral side). Immediately after the addition of the solutions samples of $20 \mu \mathrm{l}$ were taken from the apical side (volume was not replaced). The plate was incubated under gently shaking (100 rpm) at $37{ }^{\circ} \mathrm{C}, 5 \% \mathrm{CO}_{2}$ and $100 \%$ humidity. Samples of $50 \mu \mathrm{l}$ were taken after 15, 30, 60, 90, 120 and $180 \mathrm{~min}$ from the basolateral side (volume was replaced by HBSS $+5 \%$ BSA). Finally, samples of $20 \mu \mathrm{l}$ were taken from the apical side at 180 minutes and the cells were harvested from the filter inserts, by washing twice with PBS (room temperature) on both apical $(400 \mu \mathrm{l})$ and basolateral side $(1 \mathrm{ml})$. PBS was replaced by $50 \mu \mathrm{l}$ of trypsin/EDTA to allow cells to detach; then cells were re-suspended with $150 \mu \mathrm{l}$ PBS, transferred into eppendorf tubes and spun down for 5 minutes at $10621 \mathrm{~g}$ at $4{ }^{\circ} \mathrm{C}$. The supernatant was aspirated and the pellet was snap frozen in liquid nitrogen and stored at $-80{ }^{\circ} \mathrm{C}$ until analysis by LC-MS/MS. The protein content was determined using the Bio-Rad protein assay.

\section{Data analysis by LC-MS/MS}

All samples of the accumulation and transwell studies were measured using liquid chromatography coupled to mass spectrometry to determine the amount of drug (TKI) present [34]. Sample pellets were resuspended in $200 \mu \mathrm{l}$ of ice cold water and homogenized by aspiration via a pipette tip. Cell pellets of the Caco-2 monolayer were also transferred into Qiagen shredder tubes (containing QIA shredder mini spin columns) and spun down at $15800 \mathrm{~g}$ for $2 \mathrm{~min}$ to prepare a homogeneous sample. Subsequently, $20 \mu \mathrm{l}$ of each sample was transferred to 96 -well plates and $80 \mu \mathrm{l}$ of ice cold acetonitrile added. Each plate was covered with a plastic foil, sonicated for 30 seconds and centrifuged at $1500 \mathrm{~g}$ at $4{ }^{\circ} \mathrm{C}$ for $10 \mathrm{~min}$. Next, $50 \mu \mathrm{l}$ of each sample was transferred to clean 96-well plates and covered with an NUNC well plate seal. Lastly, 1 $\mu \mathrm{l}$ of each sample was injected into the LC-MS/MS. Compounds were separated on a Phenomenex prodigy ODS3, $100 \times 2 \mathrm{~mm}, 3 \mu \mathrm{m}$ column using a mobile phase containing $0.578 \mathrm{~g}$ ammonium acetate, $375 \mathrm{ml}$ MilliQ, $125 \mathrm{ml}$ methanol, $0.1 \%$ isopropanol and $1000 \mathrm{ml}$ acetonitrile with a pH of 7.8 at $500 \mu \mathrm{l} / \mathrm{min}$. Final results of the LC-MS/MS (in $\mathrm{ng} / \mathrm{ml} \mathrm{TKI)} \mathrm{were} \mathrm{expressed} \mathrm{in} \mathrm{pmol} \mathrm{(transwell)} \mathrm{or} \mathrm{combined} \mathrm{with} \mathrm{the} \mathrm{results} \mathrm{of} \mathrm{the}$ protein content determination ( $\mathrm{mg} / \mathrm{ml}$ protein), obtaining data expressed in $\mathrm{ng}$ drug per $\mathrm{mg}$ protein. 


\section{Calculations}

Apparent permeability coefficients were estimated by the following equation:

$$
P_{a p p}=\frac{\Delta Q}{\Delta t} \frac{V}{C_{0} A}
$$

where $P_{\text {app }}$ is the apparent permeability coefficient $(\mathrm{cm} / \mathrm{sec}), \Delta Q / \Delta t$ is the rate of accumulative mass transport in the receiver chamber over time $(\mu \mathrm{M} / \mathrm{sec}), V$ is the volume in the receiver chamber $(\mathrm{ml}), C_{0}$ is the concentration of TKI in the donor chamber $(\mu \mathrm{M})$ and $A$ is the diffusion area $\left(\mathrm{cm}^{2}\right)$.

\section{Results}

Temperature dependent accumulation in Caco-2 cells

Caco-2 cells were exposed to the six different TKIs under different temperature conditions to determine whether the main transport was driven by passive diffusion $\left(4^{\circ} \mathrm{C}\right)$ or by active carrier transport $\left(37^{\circ} \mathrm{C}\right)$, (Figure 2). The 2-hr time point is considered to be relevant for initial uptake; at later time-points other processes (efflux, metabolism, accumulation in cellular organelles) seem more important. After 2-hr erlotinib, gefitinib and dasatinib showed a much higher accumulation at $37{ }^{\circ} \mathrm{C}$ than at $4{ }^{\circ} \mathrm{C}$, (Figures $2 \mathrm{~A}, \mathrm{~B}$ and $2 \mathrm{~F}$, respectively); for sunitinib, crizotinib and sorafenib this difference is much less and not significantly different (Figures $2 \mathrm{C}, 2 \mathrm{D}$ and $2 \mathrm{E}$ respectively). At later time-points the pattern changes, erlotinib accumulation at $4{ }^{\circ} \mathrm{C}$ continued to increase, but at $37{ }^{\circ} \mathrm{C}$ the accumulation decreased (Figure 2A), indicating an active efflux process. Sunitinib accumulation at $37{ }^{\circ} \mathrm{C}$ continued to increase, possibly due to a lysosomal accumulation (Figure 2C) [22,39]. For crizotinib, the accumulation continued to increase under both conditions (Figure 2E), but for sorafenib no change was observed (Figure 2D).

\section{Transporter dependent hOCT dependent accumulation in Caco-2 cells}

Caco-2 cells were exposed to several inhibitors of the hOCT family in combination with the six TKIs to determine whether hOCTs are involved in the active uptake of the six TKIs (figure 3 ). The hOCT family can be inhibited by amantadine (hOCT1\&2), cimetidine (hOCT1\&2\&3) [40], desipramine (hOCT1\&2\&3), $\beta$ estradiol (hOCT1\&3) and verapamil (hOCT1\&P-gp) [27,35,36]. All five hOCT inhibitors decreased gefitinib accumulation, demonstrating that hOCT is involved in the uptake of gefitinib. Desipramine, cimetidine and $\beta$-estradiol also decreased gefitinib accumulation, indicating that hOCT3 is involved in the uptake of gefitinib. Erlotinib shows a completely different effect on the incubation with hOCT inhibitors. Verapamil, desipramine and cimetidine induced a high increase of erlotinib accumulation, in contrast to gefitinib. Amantadine and $\beta$-estradiol only induced a slight decrease of erlotinib accumulation. Therefore hOCT is not involved in erlotinib uptake. The effect of hOCT inhibitors on sunitinib and crizotinib was the same, except for verapamil. Verapamil caused a slight increase in sunitinib accumulation, but a slight decrease in crizotinib accumulation.

Desipramine decreased sunitinib and crizotinib accumulation, which indicates that hOCT1, 2 and 3 are involved in sunitinib and crizotinib uptake. Dasatinib accumulation was inhibited equally by all of the hOCT inhibitors, except for verapamil. Besides hOCT1, verapamil also inhibits P-gp, an efflux transporter, resulting in a 3-fold increase of dasatinib accumulation. These results indicate that hOCTs are involved in dasatinib influx and P-gp is involved in dasatinib efflux. The influence of the hOCT inhibitors on sorafenib accumulation is completely different, compared to dasatinib accumulation. Amantadine and $\beta$-estradiol did not show any effect and verapamil only induced a slight increase, whereas desipramine and cimetidine decreased sorafenib accumulation. 

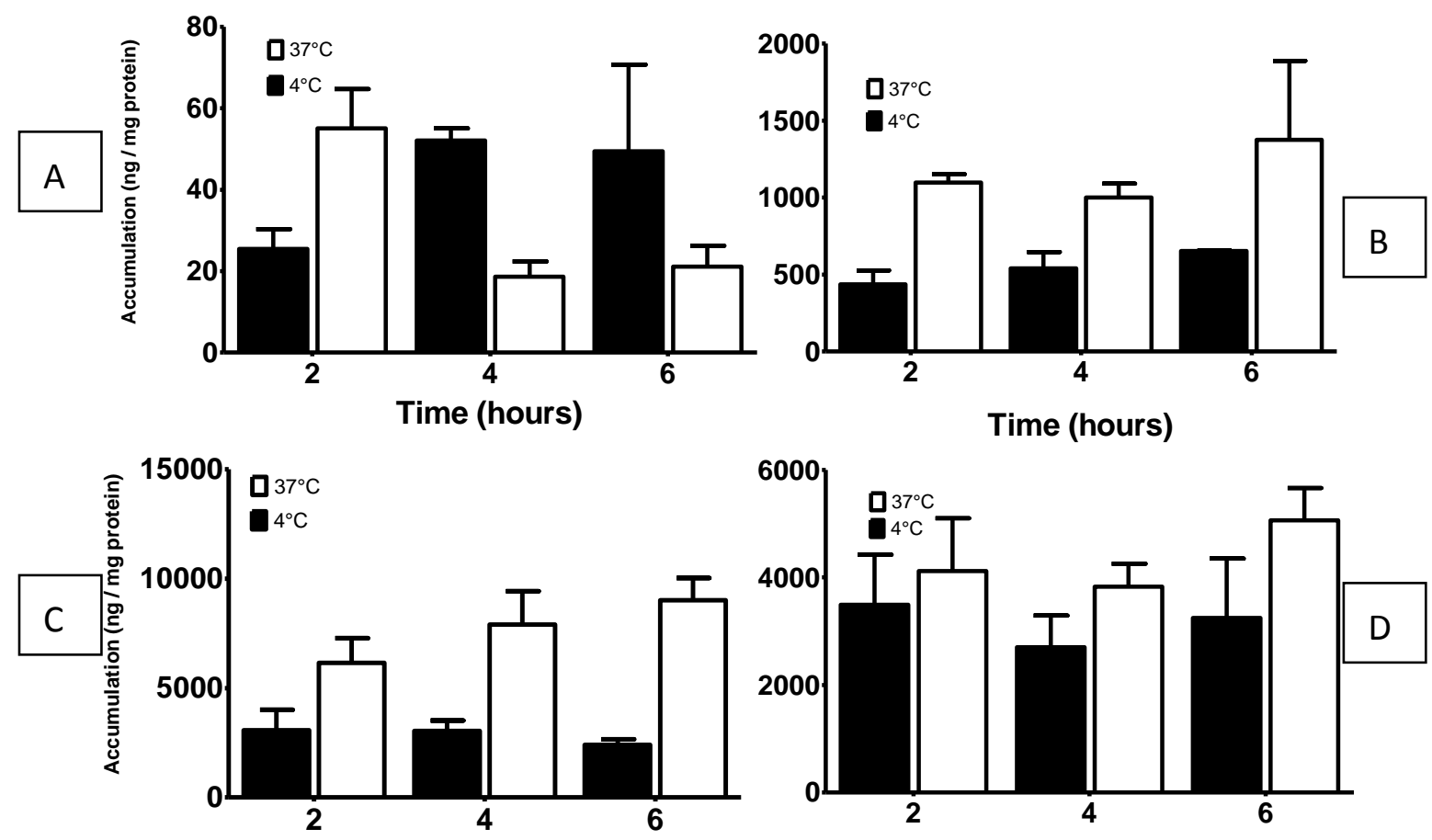

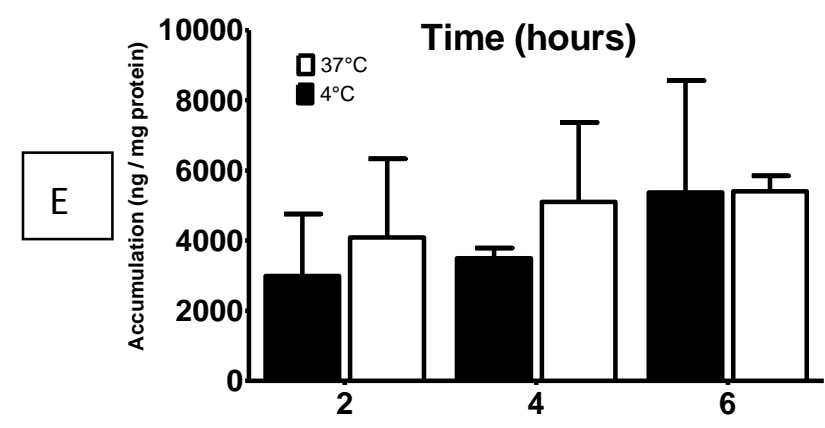

Time (hours)

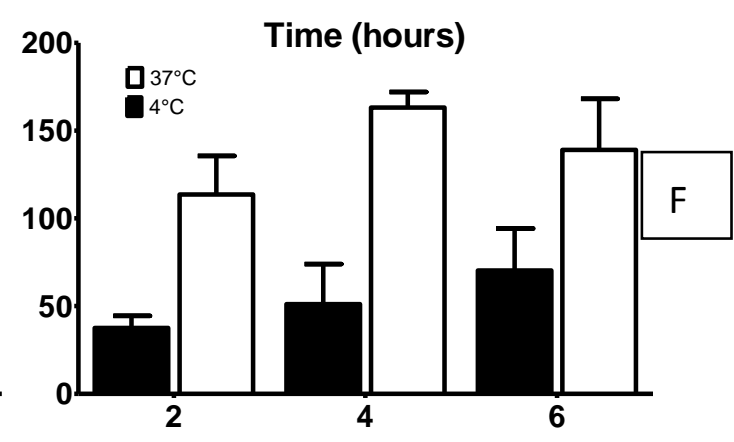

Time (hours)

Figure 2. Influence of temperature $\left(4^{\circ} \mathrm{C}\right.$ and $\left.37^{\circ} \mathrm{C}\right)$ on the cellular accumulation of $10 \mu \mathrm{M}$ erlotinib $(\mathrm{A})$; gefitinib (B); sunitinib (C); sorafenib (D); crizotinib (E) and $1 \mu \mathrm{M}$ dasatinib (F) in CaCO-2 cells. All values are reported as the Mean \pm SEM of $n=2$ and expressed as the $n g$ accumulated per $\mu \mathrm{g}$ of sample protein.

\section{Effect of hOCT inhibition basolateral transport within an intestinal model}

To further investigate the influence of hOCT on the uptake of the six TKIs, accumulation and transport studies were performed with the Becton Dickinson Bioscience BIOCOAT ${ }^{\circledR}$ HTS Caco-2 Assay System. Verapamil, desipramine and cimetidine demonstrated the most pronounced effect in the accumulation study (Figure 3), these hOCT inhibiters were used in the Transwell system. None of the three hOCT inhibitors had any effect on the apical to basolateral transport of erlotinib (Figure 4A), which is in line with the minor effect on the accumulation in Caco-2 cells (Figure 2A). However, cellular erlotinib accumulation was decreased at the end of the incubation (Figure 5).

In contrast to erlotinib, gefitinib permeation was affected by OCT inhibitors. Desipramine increased apical to basolateral transport of gefitinib (Figure 4B), yet decreased cellular gefitinib accumulation (Figure 5). Therefore, there may be increased mass transport from apical to basolateral side. Cimetidine did not affect permeation and cellular accumulation of gefitinib, while verapamil increases cellular accumulation and permeation. 


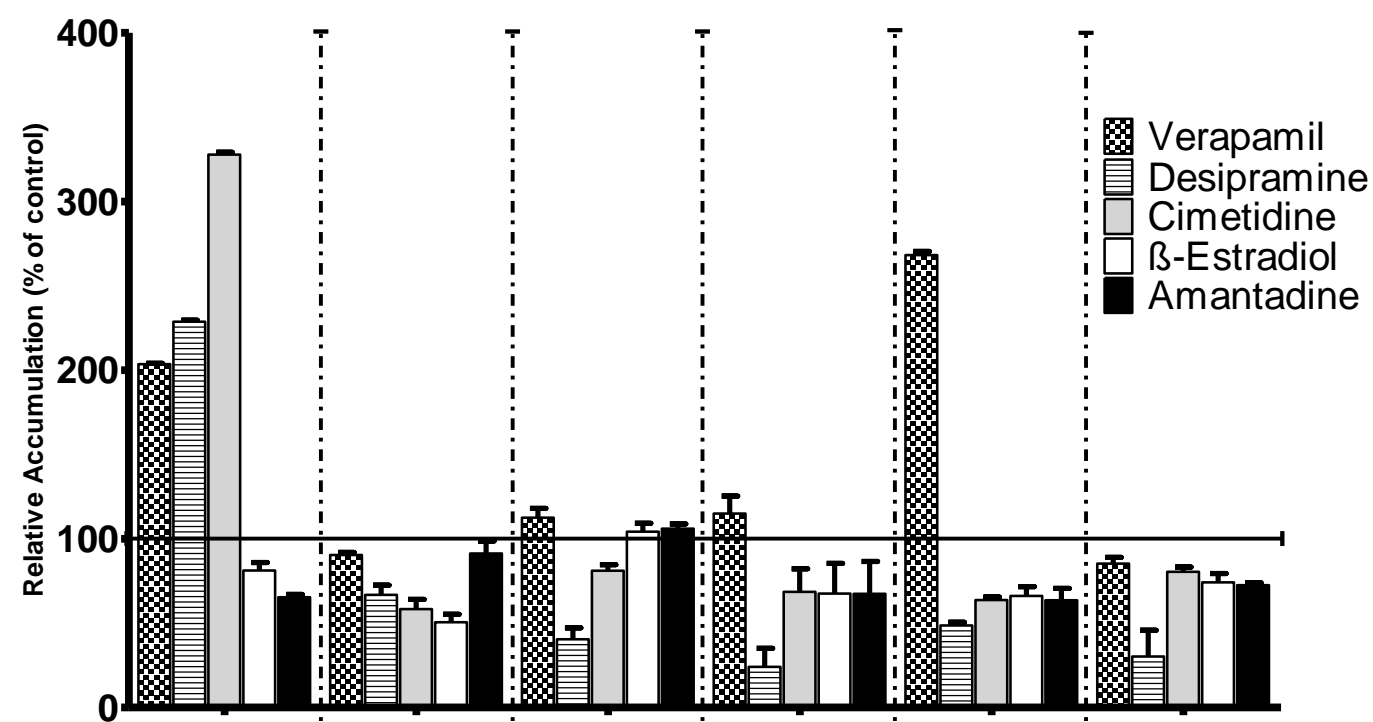

Erlotinib i Gefitinib ¿Sorafenibi Sunitinib ¿ Dasatinib_Crizotinib

Figure 3. Relative accumulation after the exposure of $10 \mu \mathrm{M}$ erlotinib, gefitinib, sorafenib, sunitinib, crizotinib and $1 \mu \mathrm{M}$ dasatinib with and without hOCT inhibitors in Caco- 2 cells (100 $\mu \mathrm{M}$ amantadine, cimetidine or desipramine; $10 \mu \mathrm{M} \beta$-estradiol and verapamil. Values are presented as percent accumulation observed relative to control (without hOCT inhibitor) of one experiment. Cellular accumulation was normalized to cell protein amount.
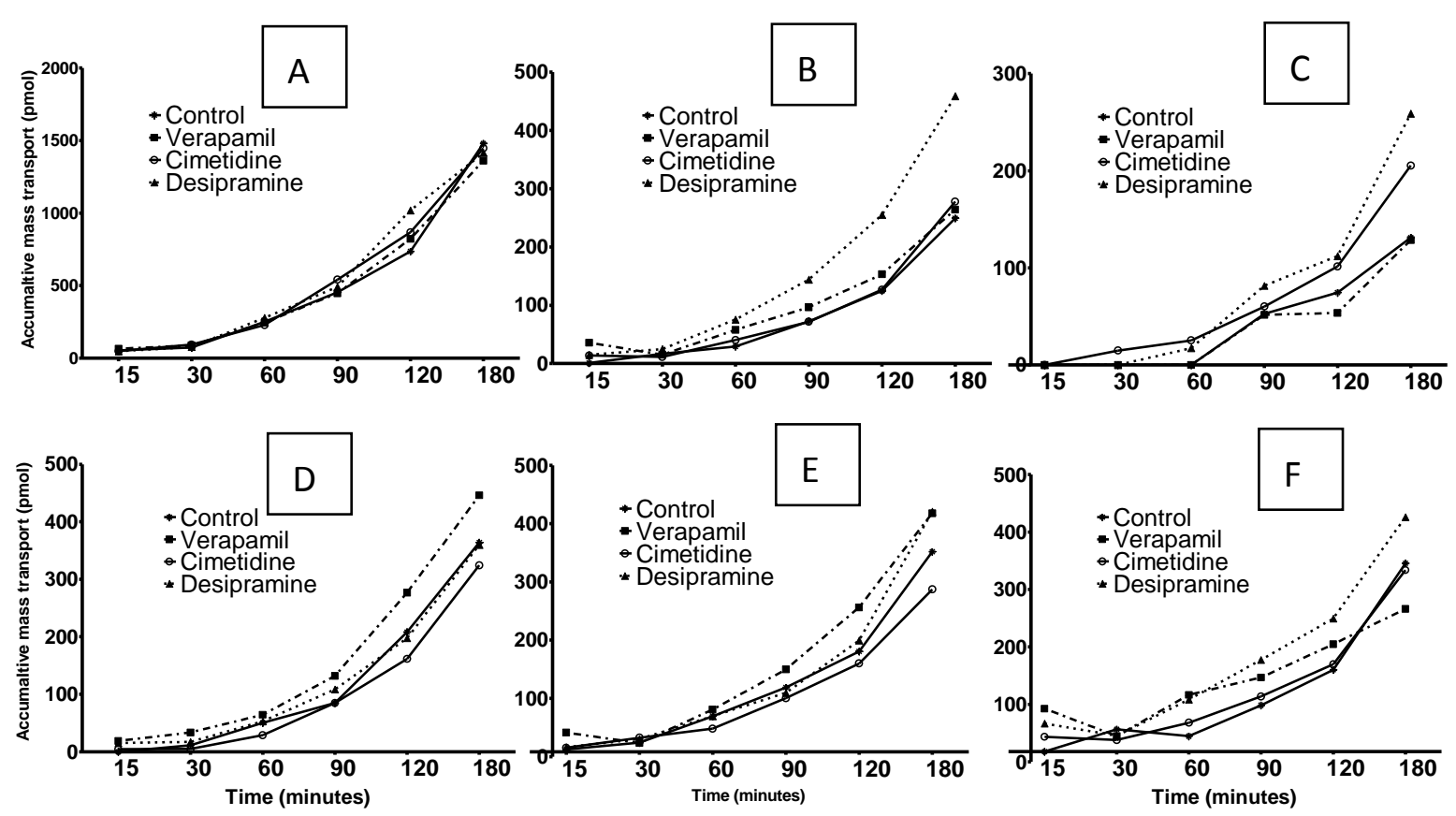

Figure 4. Accumulative mass transport from the apical to basolateral side after the exposure of $10 \mu \mathrm{M}$ of Erlotinib (A), gefitinib (B), sunitinib (F), sorafenib (D) and crizotinib (C). Dasatinib (E) was used a concentration of $1 \mu \mathrm{M}$ due to its higher activity in translational cell culture. All culturing was performed with and without the addition of either $10 \mu \mathrm{M}$ verapamil, $100 \mu \mathrm{M}$ desipramine or $100 \mu \mathrm{M}$ cimetidine. Values presented are

from one representative experiment. Cellular accumulation was normalized to cell protein amount.

The hOCT inhibitors desipramine, verapermil and cimetidine had little effect on the permeation of sunitinib, sorafenib and dasatinib (Figures 4F, 4D and 4E, respectively). However, both crizotinib (Figure 4C) and sunitinib demonstrated a small monolayer accumulation with verapamil and cimetidine whereas desipramine had little or no effect, sorafenib demonstrate little to no change in accumulation 
characteristics with all three inhibitors. However, crizotinib's permeation was increased by desipramine and cimetidine unlike sunitinib. Desipramine decreased cellular dasatinib accumulation in the transwell system while verapamil increased it, cimetidine had no effect.

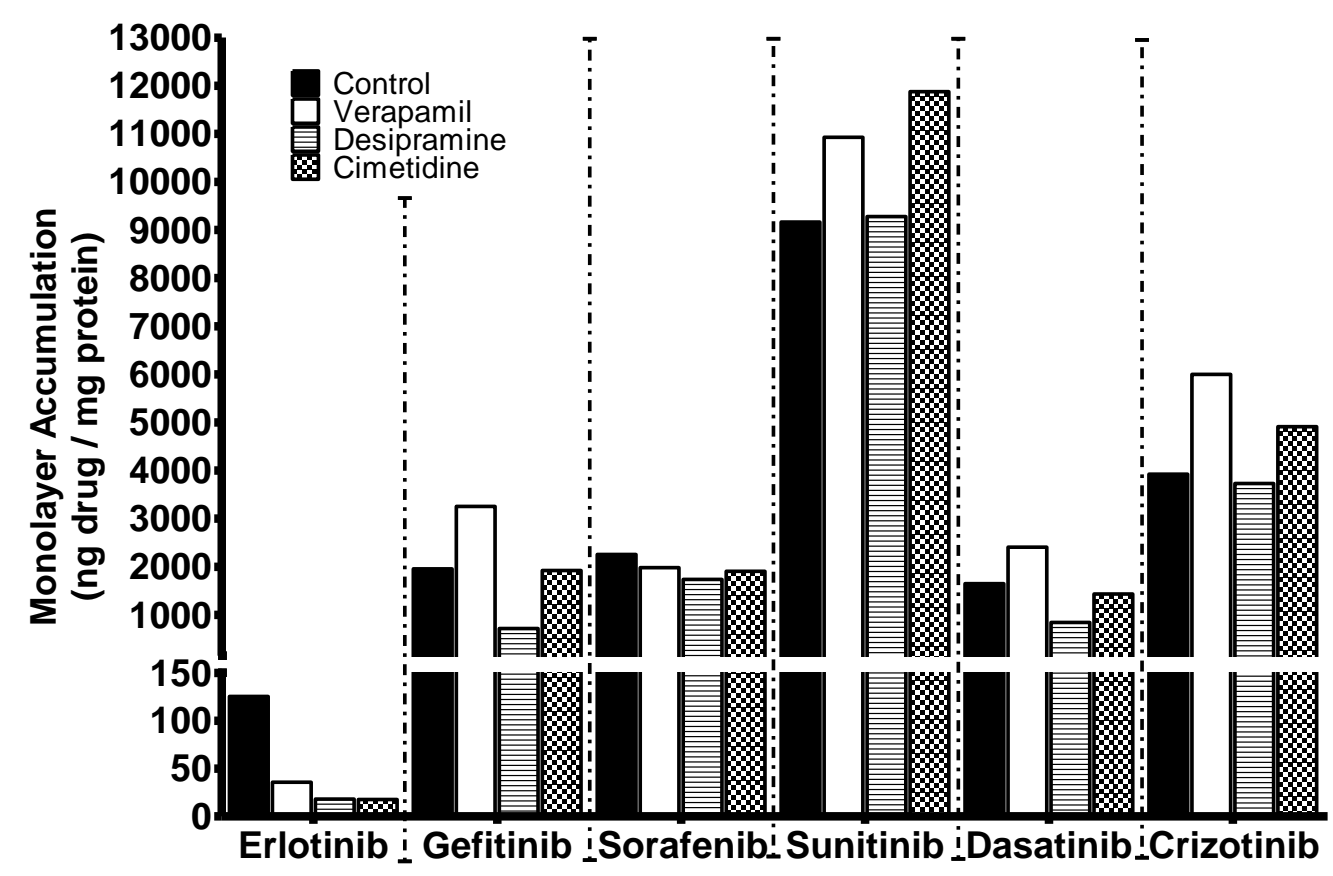

Figure 5. Following the 3 hour exposure of the monolayer to erlotinib, gefitinib, sunitinib and sorafenib, crizotinib and dasatinib the cells were harvested and analysed for TKI accumulation. Exposure was determined both with and without the addition of $10 \mu \mathrm{M}$ verapamil, $100 \mu \mathrm{M}$ desipramine or $100 \mu \mathrm{M}$ cimetidine. Values presented are from one representative experiment. Cellular accumulation was normalized to cell protein amount.

\section{Discussion}

This study demonstrated that TKIs can be transported, either passively or by an active process; for the latter both influx and efflux transporters are involved. Caco-2 cells were used by two different approaches, as a colon cancer cell line to determine the passive and active accumulation of TKI in the cells and as a model for intestinal epithelium using a transwell system as described earlier [33].

The temperature study demonstrated that uptake of crizotinib, sorafenib and sunitinib seems to be a passive process, but that of sunitinib, crizotinib and sorafenb seems to be passive. Galetti et al. [41] also studied temperature dependency of gefitnib at $4{ }^{\circ} \mathrm{C}$ and $37{ }^{\circ} \mathrm{C}$, but over a limited time period of sixty minutes with multiple points, showing a clear difference. Next to gefitinib, dasatinib uptake seemed to be predominantly an active process. However, Giannoudis et al. [42] postulated that the uptake is likely passive diffusion because of the lipophilic properties of dasatinib. On the other hand, they state that the role of other uptake transporters could not be excluded [43]. In our hands there is a clear difference between $4{ }^{\circ} \mathrm{C}$ and $37{ }^{\circ} \mathrm{C}$, indicating an active transport. Hu et al. [44] already reported that both sunitinib and sorafenib do not appear to rely on active transport to enter the cell. These drugs are also not a highaffinity substrate for the ABC- family transporters, which is in agreement with the data reported by this study. However, passive transport can be masked by the lysosomal uptake leading to more accumulation in the cell at $37^{\circ} \mathrm{C}$ as seen with sunitinib [22,39]. 
Cationic charge and high lipophilicity are requirements of OCT dependent transport of drugs [28]. Thomas et al. [27] already indicated the involvement of the human hOCT1 in the active uptake of imatinib. However, since several of the six TKIs (gefitinib, sunitinib and dasatinib) are positively charged [22] and all of the six TKIs have high lipophilic properties, we hypothesized that some of the TKIs are (partly) dependent on hOCT uptake. The results indicate that the relative accumulation decreased for all TKIs after the addition of one or more of the hOCT inhibitors except for erlotinib. Both erlotinib and dasatinib showed high relative accumulation after incubation with verapamil. This is probably due to the inhibition of P-gp, also induced by verapamil. De Vries et al. [45] also suggested the involvement of P-gp in the efflux of erlotinib. Giannoudis et al. [42] and Gromicho et al. [43] suggested that P-gp is also involved in dasatinib dependent efflux. The effect of hOCT inhibitors on sunitinib and crizotinib was similar, except for verapamil.

Both desipramine and cimetidine inhibit all three hOCTs. For most of the TKIs, desipramine induced the highest decrease of relative accumulation. The different effects of cimetidine and desipramine, despite their same inhibitor function of hOCT, might be due to concentration effects. Some hOCT inhibitors can be less effective at certain concentrations. Only cimetidine and desipramine decreased the relative accumulation of sorafenib. It is possible that all three hOCT should be inhibited to see an effect in relative accumulation of sorafenib, although Hu et al. [44] reported that sorafenib does not appear to rely on active transport to enter the cell. Nevertheless, none of the used hOCT inhibitors are specific. Therefore it cannot be concluded that the TKIs are exclusively transported by hOCT. For a better definition of the role of hOCT transporter activity in the transport of TKIs it is recommended to use more specific hOCT inhibitors such as siRNAs.

In the Caco-2 gut epithelial model system permeation is a sequential process, consisting of passive or active membrane transport at the apical site, possible trapping in the cell, and active or passive efflux at the basolateral site. Moreover transport is not limited to the apical to basolateral transport determined in this series of experiments but basolateral to apical movement from the cell could play a crucial role in the absorption of these compounds. Cimetidine, desipramine and verapamil were investigated in a model gut epithelial system to elucidate some of the relevance of the hOCT role. Due to the various locations of the different hOCTs in the intestinal model compared to the tumour model, different effects were observed. The hOCT inhibitors did not have any effect on apical to basolateral transport of erlotinib. Nevertheless an effect is seen in the accumulation of erlotinib in the Caco-2 intestinal monolayer. Therefore, verapamil, desipramine and cimetidine might act on different mechanisms within the cell. Elmeliegy et al. [46] stated that erlotinib is a substrate for hOCT2. In addition, Minematsu et al. [28] showed that erlotinib had inhibitory effects on hOCT1. In contrast to erlotinib, the hOCT inhibitor desipramine affected apical to basolateral transport of gefitinib. Since the inhibition of hOCTs by desipramine induced a higher apical to basolateral mass transport, it is suggested that the inhibition of hOCT1 (on basolateral side) had a greater effect than the inhibition of hOCT3 (on apical side), which means that there is less transport back into the cell from basolateral to apical side. The lower accumulation of gefitinib observed in the Caco- 2 intestinal monolayer after the incubation with desipramine supports this suggestion. The transport of sunitinib and crizotinib from apical to basolateral side differed. The hOCT inhibitors showed only marginal effect on sunitinib transport from apical to basolateral side. In contrast, hOCTs seem involved in the apical to basolateral transport of crizotinib. Desipramine increased mass transport of crizotinib, just like gefitinib, from apical to basolateral site. In addition, cimetidine had a similar effect as desipramine on crizotinib mass transport. The higher sunitinib and crizotinib accumulation in the Caco-2 intestinal monolayer after the incubation of verapamil and cimetidine is probably masked by lysosomal accumulation [22,39]. Just like sunitinib, sorafenib does not seem to be dependent on hOCT transport from apical to basolateral side. The 
hOCT inhibitors also showed only marginal effect on the accumulation of sorafenib in the Caco-2 intestinal monolayer. Just like sunitinib and sorafenib, dasatinib does not seem to be dependent on hOCT transport from apical to basolateral side. Dasatinib efflux is likely to be P-gp dependent and therefore an increase in dasatinib accumulation in the Caco-2 intestinal monolayer is seen after the incubation with verapamil. Desipramine decreased dasatinib accumulation in the Caco-2 intestinal monolayer, so hOCTs might be involved in basolateral to apical transport of dasatinib. Nevertheless, Giannoudis et al. [42] suggested that the uptake of dasatinib is not likely to be dependent on hOCT1 (on basolateral side). Also Gromicho et al. [43] suggested that effective uptake of dasatinib is not likely to occur with the help of hOCT1. Forchap et al. [47] concluded that dasatinib is not primarily transported by hOCT1.

It can be concluded that erlotinib is actively transported out of the cell, gefitinib and dasatinib uptake is also active while sorafenib uptake is passive. This study suggests that hOCTs might be involved in the uptake of gefitinib, sunitinib, crizotinib, sorafenib and dasatinib in the tumor model. In addition, hOCTs might be involved in the apical to basolateral transport of gefitinib and crizotinib in the intestinal model but to differing degree. Overall, it can be concluded that the six TKIs are very different in accumulation and transport.

\section{References}

[1] F. Broekman, E. Giovannetti, G.J. Peters, World J. Clin. Oncol. 2(2) (2011) 80-93.

[2] J. Schlessinger, Cell 103(2) (2000) 211-225.

[3] S.R. Hubbard, W.T. Miller, Curr. Opin. Cell Biol. 19(2) (2007) 117-123.

[4] A. Gschwind, O.M. Fischer, A. Ullrich, Nat. Rev. Cancer 4(5) (2004) 361-370.

[5] M.A. Lemmon, J. Schlessinger, Cell 141(7) (2010) 1117-1134.

[6] P.B. Allen, L.M. Wiedemann, J. Biol. Chem. 271(32) (1996) 19585-19591.

[7] D.R. Duckett, M.D. Cameron, Expert Opin. Drug Metab. Toxicol. 6(10) (2010) 1175-1193 .

[8] M.H. Cohen, J.R. Johnson, Y.-F. Chen, R. Sridhara, R. Pazdur, Oncologist 10(7) (2005) 461-466.

[9] M.H. Cohen, Oncologist 8(4) (2003) 303-306.

[10] W.S. Siegel-Lakhai, J.H. Beijnen, J.H.M. Schellens, Oncologist 10(8) (2005) 579-589.

[11] E. Lierman, I. Lahortiga, H. Van Miegroet, N. Mentens, P. Marynen, Haematologica 92(1) (2007) 2734.

[12] R.C. Kane, A.T. Farrell, R. Madabushi, B. Booth, S. Chattopadhyay, R. Sridhara, R. Justice, R. Pazdur, Oncologist 14(1) (2009) 95-100.

[13] R.C. Kane, A.T. Farrell, H. Saber, S. Tang, G. Williams, J.M. Jee, C. Liang, B. Booth, N. Chidambaram, D. Morse, R. Sridhara, P. Garvey, R. Justice, R. Pazdur, Clin. Cancer Res. 12(24) (2006) 7271-7278.

[14] R. Kumar, M.-C. Crouthamel, D.H. Rominger, R.R. Gontarek, P.J. Tummino, R.A. Levin, A.G. King, Br. J. Cancer 101(10) (2009) 1717-1723.

[15] E.P. Rock, V. Goodman, J.X. Jiang, K. Mahjoob, S.L. Verbois, D. Morse, R. Dagher, R. Justice, R. Pazdur, Oncologist 12(1) (2007) 107-113.

[16] A. Strimpakos, M.W. Saif, K.N. Syrigos, Cancer Metastasis Rev. 27(3) (2008) 495-522.

[17] M.W. Saif, JOP. J. Pancreas 12(4) (2011) 316-321.

[18] S.J. Baker, E.P. Reddy, Mt. Sinai J. Med. 77(6) (2010) 573-586.

[19] M. Brave, V. Goodman, E. Kaminskas, A. Farrell, W. Timmer, S. Pope, R. Harapanhalli, H. Saber, D. Morse, J. Bullock, A. Men, C. Noory, R. Ramchandani, L. Kenna, B. Booth, J. Gobburu, X. Jiang, R. Sridhara, R. Justice, R. Pazdur, Clin. Cancer Res. 14(2) (2008) 352-359.

[20] S.H.I. Ou, Drug Des. Devel. Ther. 5 (2011) 471-485. 
[21] I.B. Muller, A.J. De Langen, R.J. Honeywell, E. Giovannetti, G.J. Peters, Expert Rev. Anticancer Ther. 16(2) (2016) 147-157.

[22] Da Silva, C. G.; Honeywell, R. J.; Dekker, H.; Peters, G. J. Physicochemical Properties of Novel Protein Kinase Inhibitors in Relation to Their Substrate Specificity for Drug Transporters. Expert Opin Drug Metab Toxicol. 2015, 11 (1744-7607 (Electronic)), 703-717.

[23] P. Di Gion, F. Kanefendt, A. Lindauer, M. Scheffler, O. Doroshyenko, U, Fuhr, J. Wolf, U. Jaehde, Clin. Pharmacokinet. 50(9) (2011) 551-603.

[24] C. Lemos, G. Jansen, G.J. Peters, Br.J Cancer 98(5) (2008) 857-862.

[25] C. Lemos, I. Kathmann, E. Giovannetti, C. Calhau, G. Jansen, G.J. Peters, Br.J Cancer 100(7) (2009) $1120-1127$.

[26] S. Shukla, Z.-S. Chen, S.V. Ambudkar, Drug Resist. Updat. 15(1-2) (2012) 70-80.

[27] J. Thomas, L. Wang, R.E. Clark, Blood 104(12) (2004) 3739-3745.

[28] T. Minematsu, K.M. Giacomini, Mol. Cancer Ther. 10(3) (2011) 531-539.

[29] K.M. Giacomini, S.M. Huang, D.J. Tweedie, L.Z. Benet, K.L.R. Brouwer, X. Chu, A. Dahlin, R. Evers, V. Fischer, K.M. Hillgren, K.A. Hoffmaster, T. Ishikawa, D. Keppler, R.B. Kim, C.A. Lee, M. Niemi, J.W. Polli, Y. Sugiyama, P.W. Swaan, J.A. Ware, S.H. Wright, S.W. Yee, M.J. Zamek-Gliszczynski, L. Zhang, Nat. Rev. Drug Discov. 9(3) (2010) 215-236.

[30] P. Artursson, K. Palm, K. Luthman, Adv. Drug Deliv. Rev. 46(1-3) (2001) 27-43.

[31] C. Lemos, A. Faria, M. Meireles, F. Martel, R. Monteiro, C. Calhau, Eur. J. Pharmacol. 682(1-3) (2012) 37-42.

[32] M. Roth, A. Obaidat, B. Hagenbuch, Br. J. Pharmacol. 165(5) (2012) 1260-1287.

[33] R. Honeywell, C. Fatmawati, M. Buddha, S. Hitzerd, I. Kathman, G. Peters, ADMET and DMPK 3(1) (2015) 51-67.

[34] R. Honeywell, K. Yarzadah, E. Giovannetti, N. Losekoot, E.F. Smit, M. Walraven, J.S. W.Lind, C. Tibaldi, H.M. Verheul, G.J. Peters, J. Chromatogr. B Anal. Technol. Biomed. Life Sci. 878(15-16) (2010) 1059-1068.

[35] C. Pauli-Magnus, O. von Richter, O. Burk, A. Ziegler, T. Mettang, M. Eichelbaum, M.F. Fromm, J. Pharmacol. Exp. Ther. 293(2) (2000) 376-382.

[36] H. Koepsell, B.M. Schmitt, V. Gorboulev, Rev. Physiol. Biochem. Pharmacol. 150 (2003) 36-90.

[37] S. Chong, S.A. Dando, R.A. Morrison, Pharm. Res. 14(12) (1997) 1835-1837.

[38] S. Yamashita, K. Konishi, Y. Yamazaki, Y. Taki, T. Sakane, H. Sezaki, Y. Furuyama, J. Pharm. Sci. 91(3) (2002) 669-679.

[39] K.J. Gotink, H.J. Broxterman, M. Labots, R.R. de Haas, H. Dekker, R.J. Honeywell, M.A. Rudek, L.V. Beerepoot, R.J. Musters, G. Jansen, A.W. Griffioen, Y.G. Assaraf, R. Pili, G.J. Peters, H.M.W. Verheul, Clin.Cancer Res. 17(23) (2011) 7337-7346.

[40] W.-K. Lee, M. Reichold, B. Edemir, G. Ciarimboli, R. Warth, H. Koepsell, F. Thévenod, Am. J. Physiol. Renal Physiol. 296(6) (2009) F1504-F1513.

[41] M. Galetti, R.R. Alfieri, A. Cavazzoni, S. La Monica, M. Bonelli, C. Fumarola, P. Mozzoni, G. De Palma, R. Andreoli, A. Mutti, M. Mor, M. Tiseo, A. Ardizzoni, P.G. Petronini, Biochem. Pharmacol. 80(2) (2010) 179-187.

[42] A. Giannoudis, A. Davies, C.M. Lucas, R.J. Harris, M. Pirmohamed, R.E. Clark, Blood 112(8) (2008) 3348-3354.

[43] M. Gromicho, J. Dinis, M. Magalhães, A.R. Fernandes, P. Tavares, A. Laires, J. Rueff, A.S. Rodrigues, Leuk. Lymphoma 52(10) (2011) 1980-1990.

[44] S. Hu, Z. Chen, R. Franke, S. Orwick, M. Zhao, M. Rudek, A. Sparreboom, S.D. Baker, Clin. Cancer Res. 15(19) (2009) 6062-6069.

[45] N. De Vries, T. Buckle, J. Zhao, J.H. Beijnen, J.H.M. Schellens, O. Van Tellingen, Invest. New Drugs 30(2) (2012) 443-449. 
[46] M.A. Elmeliegy, A.M. Carcaboso, M. Tagen, F. Bai, C.F. Stewart, Clin. Cancer Res. 17(1) (2011) 8999.

[47] S.L. Forchap, M. Pirmohamed, R.E. Clark, Leukemia 26(3) (2012) 490-498.

(C)2016 by the authors; licensee IAPC, Zagreb, Croatia. This article is an open-access article distributed under the terms and conditions of the Creative Commons Attribution license (http://creativecommons.org/licenses/by/3.0/) (cc) E EY 